\title{
Demographic and Clinical Characteristic of Tuberculosis among Patients in Al Wihda TB Center in Al-Falluja/Iraq
}

\author{
Mahmood H. Mahmood ${ }^{\star, \dagger, 1}$, Aeshah M. Hameed ${ }^{2}$
}

${ }^{1}$ M.B.CH.B, DPLOMA, College of Medicine, Al-Mosel University

${ }^{2}$ M.B.CH.B, College of Medicine, Al-Anbar University

(DDOI: https://doi.org/10.15520/jcmro.v2i11.231

Accepted 07-11-2019; Received 20-10-2019; Publish Online 10-11-2019

Reviewed By:
Dr. Dhary Almashhadany
Department:
Reviewer/CMRO

\section{ABSTRACT \\ Background:}

Tuberculosis (TB) is an infectious disease caused by mycobacterium tuberculosis, affect mainly the lungs (pulmonary TB) but can affect any other part of the body (extra pulmonary TB).

Objectives:

This was a retrospective study focused on a one-year period from 1st January 2018-31st December 2018 to describe the demographic and clinical characteristic tuberculosis (TB) among patients in Al Wihda TB health center in AL-Falluja/Iraq

Method:

the following data were studied from patient record at Al WIHDA TB health center in AL-Falluja /Iraq (age, gender, address, symptoms, type of patients, site of TB, outcome)

\section{Results:}

The total number of patients were 60 cases, female were affected more than male, the ratio (female $36=60 \%$ and male $2=60 \%$ ). The most common first presenting compliant were fever and night sweating with cough and sputum. Most of the patients presented at the age of (15_44) year. intrapulmonary (PTB) in 32 cases (53\%), extrapulmonary (EPTB) in 28 cases $(47 \%)$. PTB was smear (SS)+ in 30\%, (SS)- in 8\%, $\mathrm{N}(\mathrm{S}-)$ (ND) $5 \%$, relapse in 5(12\%) PTB was confirmed only by chest X-ray and DSM. Treatment was completed 38(63\%), 17 (28\%) were cured, transfer $4(7 \%)$ and death in $1(2 \%)$.

Conclusion:

Our main findings are:

$1 / \mathrm{TB}$ in our area is a disease of a low education and poor people.

2/Extra-pulmonary TB (EPTB)was more frequent (47\%), and, more specifically, pleura (46\%).

$3 /$ female patients had experienced detected cases of tuberculosis more than male.

4/Age group of (15-24) year old had experienced detected cases of TB more than other age group.

5/New extra-pulmonary TB (EPTB) is the type in female patient, while new pulmonary TB (PTB) (SS+) is the type in male patient.

were complain commonly from fever and sweating, cough usually with whitish sputum, weight loss and chest pain.

Other were complain from loss of appetite and there was no complaining of hemoptysis.

Recommendation: By based on the conclusion, our study can recommend that:

1. Increase individuals and patients' awareness to wared tuberculosis as public health problem and the benefits of its treatment.

2. Effective attention about the people at risk by Ministry health program.

\section{Abbreviation:}

TB: tuberculosis. PTB: pulmonary tuberculosis

EPTB: Extra-pulmonary tuberculosis. N (SS+): New Sputum Smear Positive.

N (SS-): New Sputum Smear Negative. DSM: Direct Sputum Smear Microscopy.

HIV: Human Immunodeficiency Virus. WHO: world Health Organization.

IGRAs: Interferon Gamma Release Assay. CDR: Case detection rate.

RR: Rifampicin resistance. MDR-TB: Multidrug resistance.

Key words: Tuberculosis-Prevalence-Al-Falluja. 


\section{INTRODUCTION:}

Tuberculosis is one of the top 10 causes of death and the leading cause from a single infectious agent (above HIV/AIDS).Millions of people continue to fall sick with TB each year. [1] In 2017, TB caused an estimated 1.3 million deaths (range, 1.2-1.4) among HIV-negative people and there were an additional 300000 deaths from TB (range, 266 000-335 000) among HIV-positive people [2]

In 2017, the largest number of new TB cases occurred in the South- East Asia and Western Pacific region, with $62 \%$ of new cases, followed by African region, with $25 \%$ of new cases [3]

Iraq is considered to be a middle burden country with TB, and occupies rank 108 globally and 7 in eastern Mediterranean region among countries with TB burden size. According to WHO report, the estimated incidence of TB in Iraq is $45 / 100000$ population (I.e estimated total new TB cases is around 15000 per year), while the prevalence is $74 / 100000$ and the mortality is $3 / 100000$ [4].

In most cases, the infection is caused by inhaling the tuberculosis bacilli from the infected person by coughing or sneezing, talk and in a few cases by drinking milk contaminated with tuberculosis bacilli, or the person is sharing the infectious patient in his tools, personal instruments, and rarely through the skin [5].

This study intended to investigate the prevalence of TB detected cases which attended Al-Wihda TB health center in AL-Falluja city, Iraq for period 1st January/2018 to 31st December $/ 2018$.

\section{METHODOLOGY:}

A "retrospective" study design was employed throughout this study from the period of 20th July to August 24th , 2019 in order to detect the TB cases in AL-Falluja city for 2018. A sample of 60 patients with tuberculosis was regis-tered in AL-Falluja city for 2018. These patients were with different age groups from months to 65 year of age. It consist of collection about the (age, gender, address, symptom, type of patient, site of TB, outcome) from registered data of TB patients in AL-Wihda health center, Falluja city.Table 1Table 2Tables 3 and 4Table 5Figures 1 and 2

Figure 1: show sweating and fever were the most symp-toms that the patient complaining from them with cough that is usually associated with whitish sputum in most of the patients.

Figure 2: show most the patient have new infection without relation to the previous history of TB or positive family history.

\section{DISCUSSION:}

This study describes the Demographic and clinical characteristics of patients with TB and their outcome in one-year

* Corresponding author.

† Email: wmowm55@gmail.com
Table 2. Distribution of patients according to the age group.

\begin{tabular}{lll}
\hline Age group & $\begin{array}{c}\text { Number Perercentage } \\
\text { of }\end{array}$ \\
& cases \\
$0-1$ & 1 & $2 \%$ \\
$1-4$ & 3 & $5 \%$ \\
$5-14$ & 6 & $10 \%$ \\
$15-24$ & 13 & $22 \%$ \\
$25-34$ & 11 & $18 \%$ \\
$35-44$ & 9 & $15 \%$ \\
$45-54$ & 4 & $7 \%$ \\
$55-64$ & 7 & $12 \%$ \\
$65-75$ & 6 & $10 \%$ \\
Total & 60 & $100 \%$ \\
\hline
\end{tabular}

Table 2: prevalence ofTB among the age groups show that the the age group from 15 to 34 year of ageis most affected.(22\%) for theage group (15-24) and (18\%) for the age group(25-34) which are the most economically productive age groups.

Table 4. EPTB sub-diagnosis

\begin{tabular}{lll}
\hline Site & Number of cases & Percentage \\
Lymph node & 9 & $32 \%$ \\
Pleura & 13 & $46 \%$ \\
Bone and Vertebra & 3 & $11 \%$ \\
Miliary TB & 1 & $4 \%$ \\
Meninges & 1 & $4 \%$ \\
Others & 1 & $4 \%$ \\
Total & 28 & $47 \%$ \\
\hline
\end{tabular}

Table 4 : shows that the most affected sites were the pleura $(46 \%)$ and the lymph node $(32 \%)$

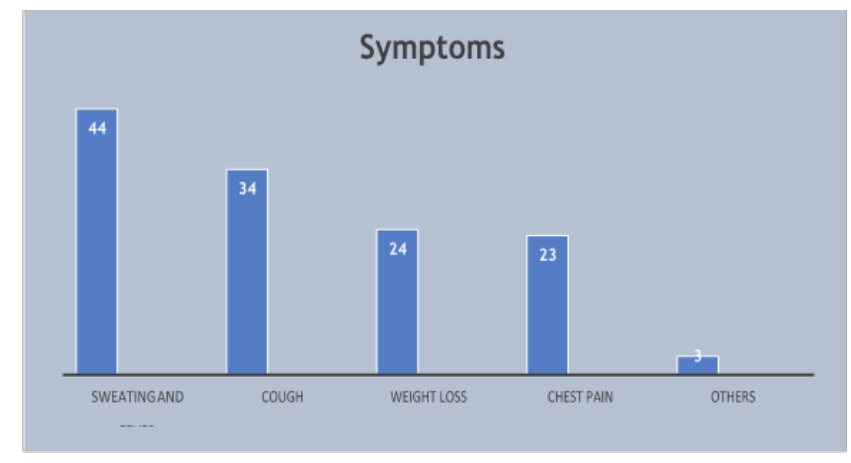

Figure 1. symptoms of the TBpatients

Table 5. outcome of patients

\begin{tabular}{lll}
\hline Outcome & Number of cases & Percentage \\
Cure & 17 & $28 \%$ \\
Complete & 36 & $60 \%$ \\
Transfer & 4 & $7 \%$ \\
Death & 1 & $2 \%$ \\
Rifampicin resistant & 2 & $3 \%$ \\
Total & 60 & $100 \%$ \\
\hline
\end{tabular}

Table 5 : show most of patients were completed their treatment $(60 \%),(28 \%)$ cured, $(7 \%)$ transfer to another health center, $(3 \%) \mathrm{RR}$ and $(2 \%)$ death 


\section{Demographic and Clinical Characteristic of Tuberculosis among Patients in Al Wihda TB Center in Al-Falluja/Iraq

Table 1. Distribution of case according to address and gender.

\begin{tabular}{lclllll}
\hline $\begin{array}{l}\text { Name of health } \\
\text { center }\end{array}$ & $\begin{array}{l}\text { Number } \\
\text { of Cases }\end{array}$ & \multicolumn{2}{c}{ Percentage } & \multicolumn{3}{c}{ Gender } \\
Al-Jumhuriya & 2 & $3 \%$ & - & - & 2 & \\
AL-Karma & 9 & $15 \%$ & 7 & $78 \%$ & 2 & $22 \%$ \\
AL-Saqlawyia & 6 & $10 \%$ & 4 & $67 \%$ & 2 & $33 \%$ \\
AL-Cement & 5 & $8 \%$ & 1 & $20 \%$ & 4 & $80 \%$ \\
AL-Wihda & 4 & $7 \%$ & 1 & $25 \%$ & 3 & $75 \%$ \\
Nazal & 12 & $20 \%$ & 2 & $17 \%$ & 10 & $83 \%$ \\
Jubail & 13 & $22 \%$ & 4 & $31 \%$ & 9 & $69 \%$ \\
AL-Shuhadaa & 6 & $10 \%$ & 2 & $33 \%$ & 4 & $67 \%$ \\
AL-Julan & 3 & $5 \%$ & 1 & $33 \%$ & 2 & $67 \%$ \\
Total & 60 & $100 \%$ & 24 & $40 \%$ & 36 & $60 \%$ \\
\hline
\end{tabular}

Table $1:$ Result out of this table showed that most of patients were from Jubail and Nazal which involve the low education and the poorest people and most patients were females . In Jubail there were (22\%)of cases, males (31\%) and females (69\%).In Nazal $(20 \%)$ of cases, males $(17 \%)$ and females $(83 \%)$

Table 3. Distribution of cases according to the type of patient and gender.

\begin{tabular}{lclllcl}
\hline Type of patient & $\begin{array}{c}\text { Number of Persantage } \\
\text { cases }\end{array}$ & & Male & Percentage & Femaler & Percentage \\
New PTB (SS+) & 18 & $30 \%$ & 10 & $56 \%$ & 8 & $44 \%$ \\
Relapse & 5 & $8 \%$ & 1 & $40 \%$ & 4 & $80 \%$ \\
New PTB(SS-) & 5 & $8 \%$ & 1 & $20 \%$ & 4 & $80 \%$ \\
New (EP) & 28 & $47 \%$ & 12 & $43 \%$ & 16 & $54 \%$ \\
New PTB (S-)(ND) & 3 & $5 \%$ & - & - & 3 & $100 \%$ \\
After default & 1 & $2 \%$ & - & - & 1 & $100 \%$ \\
Total & 60 & $100 \%$ & 24 & $40 \%$ & 36 & $60 \%$ \\
\end{tabular}

Table 3 : show the most type of patients were EPTB $(47 \%)$ and the new PTB(SS+)(30\%).female was most affected than male with EPTB while male was most affected than female with $\mathrm{N}(\mathrm{SS}+)$.Relapse and all other type except $\mathrm{N}(\mathrm{SS}-)$, were more detected in female than male patients.

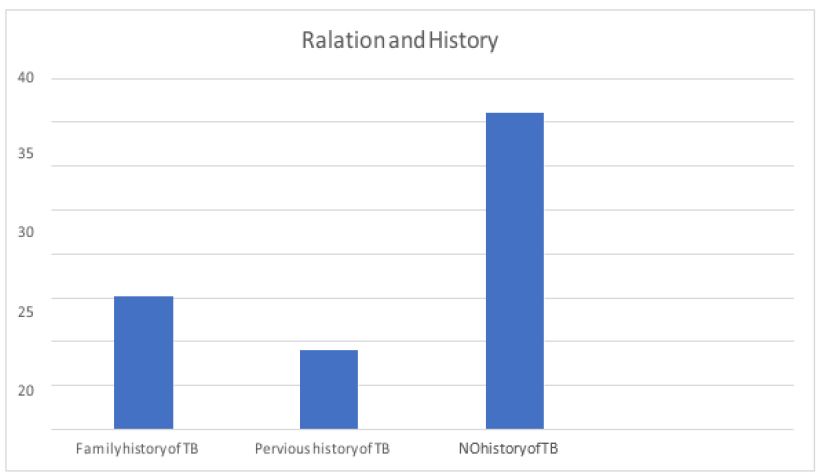

Figure 2. Relation between TB and the presence of previous orfamily history

period in Al-Falluja city. We depend on documented data in patients' records in Al-Wihda health center. Initially, they were complain from many of constitutional symptoms besides chest symptoms.15-30 days as a time range between the first manifestation and the diagnosis with TB, indicating the delayed presentation of patients to health care facilities for TB diagnosis. This may be due to lack of knowledge of symptom presentation, and financial barriers faced by patients.

TBP was confirmed only by chest X-ray and DSM (Direct Sputum Smear Microscopy) with absence of Xpert and IGRA in Al-Wihda health center. Case detection rate (CDR) of (NS+) was $20.5 \%$ for

2018." Case Detection Rate (CDR)is still used as a primary indicator to measure case finding at all levels, even though it is not recommended by WHO to be used at subnational levels. In addition, CDR is not even measurable at subnational level as there are currently no subnational estimate of incidence" (6). All patients had received first line of TB drugs that include category I (NS+,NS-,NEPTB, unknown TB history) and category II (Relapse, failure, loss to follow up) with (Isoniazid, rifampicin, ethambutol, pyrazinamide) used on two phases initial phase (2 months) and continuation phase (4 months). Most the patients did not have previous history or family history ,some of them had either previous history or family history There was screening and preventive therapy for the contact at risk but really was limited. while others had experience with both of them. There was screening and preventive therapy for the contact at risk but really was limited. The outcome of the patients was complete their treatment with detection of two cases had resistant to rifampicin but there was no one case with MDR. 


\section{CONCLUSION:}

\section{Our main findings are:}

$1 / \mathrm{TB}$ in our area is a disease of a low education and poor people.

2/Extra-pulmonary TB (EPTB)was more frequent $(47 \%)$, and, more specifically, pleura $(46 \%)$.

$3 /$ female patients had experienced detected cases of tuberculosis more than male.

4/Age group of (15-24) year old had experienced detected cases of TB more than other age group.

$5 /$ New extra-pulmonary TB (EPTB) is the type in female patient, while new pulmonary $\mathrm{TB}(\mathrm{PTB})(\mathrm{SS}+)$ is the type in male patient.

6 / The patients were complain commonly from fever and night sweating, cough that was usually with whitish sputum, weight loss and chest pain.

Other were complain from loss of appetite and fatigue.There was no complaining of hemoptysis.

\section{Recommendation:}

By based on the conclusion, our study can recommend that:

1. Increase individuals and patients' awareness to wared tuberculosis as public health problem and the benefits of its treatment.

2. Effective attention about the people at risk by the health program.

\section{REFERENCES}

[1] Global health observatory (GHO) data> tuberculosis.

[2] Tuberculosis-World Health Organization, 2018.

[3] WHO (2009) epidemiology (PDF), Global tuberculosis control epidemiology, strategy, financy p.p6-33

[4] National Tuberculosis Management guideline, 2018.

[5] Joint Tuberculosis Program review, Philippines ,2016. 